\title{
Parasites of importance for human health in Nigerian dogs: high prevalence and limited knowledge of pet owners Uade Samuel Ugbomoiko ${ }^{1}$, Liana Ariza ${ }^{2}$ and Jorg Heukelbach*3,4
}

Address: ${ }^{1}$ Department of Zoology, University of Ilorin, Nigeria, ${ }^{2}$ Post-Graduation Program in Medical Sciences, School of Medicine, Federal University of Ceará, Brazil, ${ }^{3}$ Department of Community Health, School of Medicine, Federal University of Ceará, Rua Prof. Costa Mendes 1608 , 5. andar, Fortaleza CE 60430-140, Brazil and ${ }^{4}$ Anton Breinl Centre for Public Health and Tropical Medicine, School of Public Health, Tropical Medicine and Rehabilitation Sciences, James Cook University, Townsville, Australia

Email: Uade Samuel Ugbomoiko - samugbomoiko@yahoo.com; Liana Ariza - arizaliana@hotmail.com; Jorg Heukelbach* - heukelbach@web.de

* Corresponding author

Published: 9 December 2008

BMC Veterinary Research 2008, 4:49 doi:10.1 |86/1746-6/48-4-49
Received: 25 July 2008

Accepted: 9 December 2008

This article is available from: http://www.biomedcentral.com/l746-6/48/4/49

(c) 2008 Ugbomoiko et al; licensee BioMed Central Ltd.

This is an Open Access article distributed under the terms of the Creative Commons Attribution License (http://creativecommons.org/licenses/by/2.0), which permits unrestricted use, distribution, and reproduction in any medium, provided the original work is properly cited.

\begin{abstract}
Background: Dogs are the most common pet animals worldwide. They may harbour a wide range of parasites with zoonotic potential, thus causing a health risk to humans. In Nigeria, epidemiological knowledge on these parasites is limited.
\end{abstract}

Methods: In a community-based study, we examined 396 dogs in urban and rural areas of llorin (Kwara State, Central Nigeria) for ectoparasites and intestinal helminths. In addition, a questionnaire regarding knowledge and practices was applied to pet owners.

Results: Nine ectoparasite species belonging to four taxa and six intestinal helminth species were identified: fleas (Ctenocephalides canis, Pulex irritans, Tunga penetrans), mites (Demodex canis, Otodectes sp., Sarcoptes scabiei var. canis), ticks (Rhipicephalus sanguineus, Ixodes sp.), and lice (Trichodectes canis); and Toxocara canis, Ancylostoma sp., Trichuris vulpis, Dipylidium caninum, Taenidae and Strongyloides sp. Overall prevalence of ectoparasites was $60.4 \%$ and of intestinal helminths $68.4 \%$. The occurrence of $C$. canis, $R$. sanguineus, $T$. canis, Ancylostoma sp. and T. vulpis was most common (prevalence $14.4 \%$ to $41.7 \%$ ). Prevalence patterns in helminths were age-dependent, with $T$. canis showing a decreasing prevalence with age of host, and a reverse trend in other parasite species. Knowledge regarding zoonoses was very limited and the diseases not considered a major health problem. Treatment with antiparasitic drugs was more frequent in urban areas.

Conclusion: Parasites of importance for human health were highly prevalent in Nigerian dogs. Interventions should include health education provided to dog owners and the establishment of a program focusing on zoonotic diseases.

\section{Background}

Dogs are the most successful canids, adapted to human habitation worldwide. They have contributed to physical, social and emotional well-being of their owners, particularly children $[1,2]$. However, in spite of the beneficial effects, close bonds of dogs and humans (in combination with inappropriate human practices and behaviour) remain a major threat to public health, with dogs harbouring a bewildering number of infective stages of parasites transmissible to man and other domestic animals [2- 
4]. For example, well-known and important zoonotic diseases are cutaneous and visceral larva migrans, hydatid disease and tungiasis [5-8].

In low-income settings, treatments to eliminate these parasites are - if done at all - often applied in advanced stages of disease, causing distress on pets and their owners $[9,10]$.

In many African countries, including Nigeria, appropriate policies regarding pet ownership and their effects on individual and community health are nonexistent. Prevalence of parasite infection in dogs with importance for human health is usually high, resulting in risk of zoonotic transmission from dogs to humans. The risk is further increased by non-favourable ecological and human behavioural factors [11-13].

Previous epidemiological studies on dog parasites in Nigeria were focused on the prevalence with little or no information on quantitative measure of infection and/or were not community-based [14-17]. Thus, we examined a representative population of dogs in urban and rural areas in a Nigerian city for the presence of possibly zoonotic parasites.

\section{Methods}

\section{Study Area}

The study was conducted in the city of Ilorin (Central Nigeria), and the neighbouring rural communities (longitude $4^{\circ} 30^{\prime}-4^{\circ} 45^{\prime} \mathrm{N}$ and latitude $8^{\circ} 28^{\prime}-8^{\circ} 38^{\prime} \mathrm{E}$; Figure 1). Ilorin is an urban centre and the capital of Kwara State. The city covers an area of about 38 square miles, with an estimated population of 1.4 million people. It is located in Nigeria's central savannah region with intense rainfalls from April to October and daily temperatures between $23^{\circ} \mathrm{C}$ and $37^{\circ} \mathrm{C}$.

The urban area of Ilorin is surrounded by rural villages with mainly agricultural-based economy. Living conditions are particularly poor in these rural communities, and a substantial proportion of the villagers keeping dogs have no access to veterinary services. Therefore, most dogs have never been treated for any form of parasitic diseases prior to the study. In addition, most dogs are not vaccinated.

\section{Study design}

A random house-to-house screening of dogs was conducted between October 2006 and May 2007. With the informed consent of dog owners, interviews were conducted using pre-tested structured questionnaires to obtain information on the dogs' age, sex, regimen, defaecation sites, previous anthelminthic treatment and disease-related knowledge of owners. Thereafter, pre-labeled specimen containers were distributed for the collection of stool samples. A screening of ectoparasites on dogs was performed before fecal specimen collection.

In households with more than one dog, only one dog (chosen by the dog owner) was included.

\section{Sample collections}

Dogs were thoroughly examined for ectoparasites by combing the entire body surfaces on a clear sheet of white paper. To facilitate the extraction of ectoparasites, the
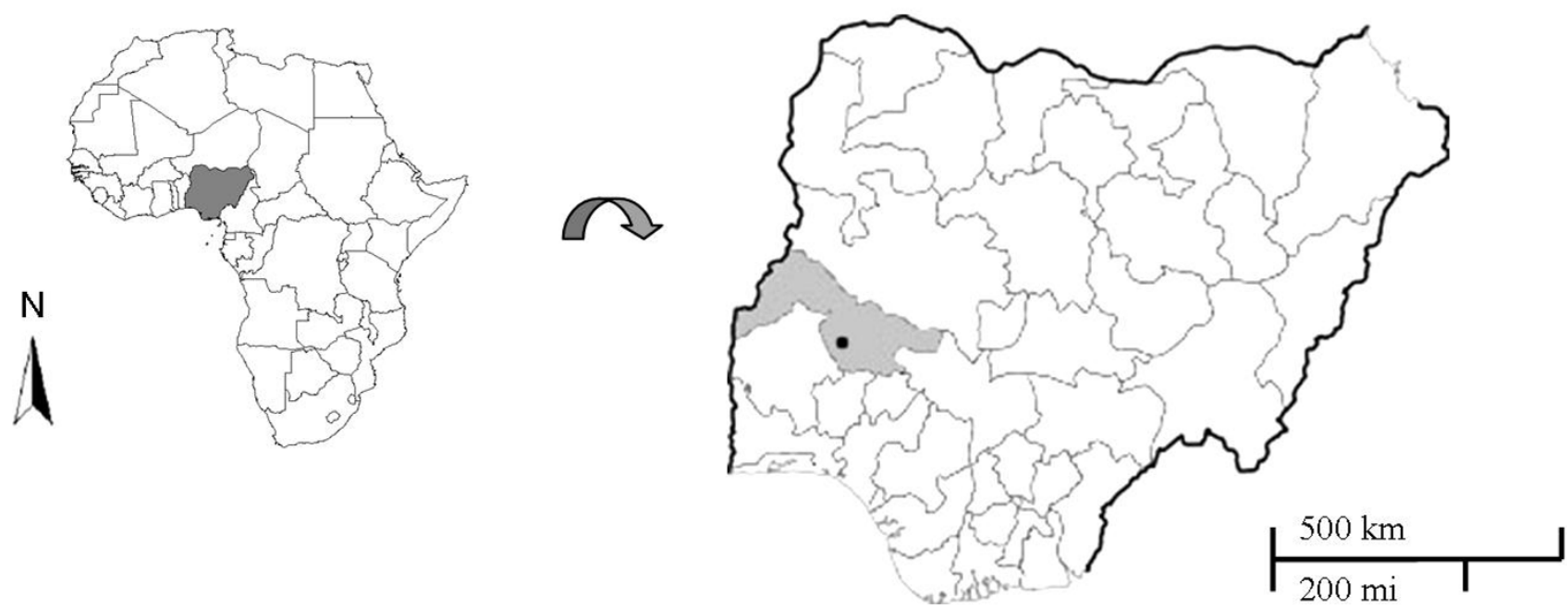

Figure I

Map of the study area highlighting Nigeria (left), Kwara State and the study area (right). 
dogs were rubbed with a piece of cotton-wool soaked in ether. The ectoparasites recovered were preserved in $70 \%$ alcohol for identification.

For the diagnosis of intestinal helminths, freshly passed faecal samples from dogs were collected from dog owners and examined macroscopically for proglottides. Thereafter, a sub-sample of faeces was taken into a pre-labelled clean sterile universal plastic bottle containing $10 \%$ formaldehyde solution. All samples were carried to the parasitology laboratory at the University of Ilorin and processed for microscopic examination.

\section{Laboratory procedures}

Fleas, ticks and lice were cleared in $10 \%$ potassium hydroxide $(\mathrm{KOH})$ solution overnight, dehydrated in ascending strength of alcohol and mounted in Canada balsam. Mites were mounted directly in Berlese fluid. Examination was done at $40 \times$ magnification under a dissecting microscope.

A duplicate $50 \mathrm{mg}$ Kato-Katz thick smear was prepared from each faecal sample, using the Kato-Katz technique, as modified by Forrester and Scott [18]. In short, a small portion (1-3 g) was sieved through double-ply gauze to remove rough materials. The filtrate was centrifuged at $3000 \mathrm{rpm}$ for $3 \mathrm{~min}$, the supernatant decanted, and the tube allowed to stand for $10 \mathrm{~min}$. Fifty $\mathrm{mg}$ of the sediment delivered by Kato-Katz template was taken onto a degreased glass slide, and covered with a cellophane strip soaked overnight in $50 \%$ solution of glycerol-malachite green. Slides were examined for helminths eggs under a light microscope immediately after preparation. Parasite eggs were identified based on the morphological characteristics. Density of infection, as expressed by eggs per gram (EPG) of faeces, was calculated by multiplying each slide count by 20 [19].

\section{Data Entry and Statistical Analysis}

Data were entered using an excel spreadsheet and checked for entry errors, by comparing data entries with the original data forms. Then, data were transferred to Stata ${ }^{\circledast}$ software package (version 9.0; Stata Corporation, College Station, USA) for analysis. The Fisher's exact test was applied to determine the significance of differences of relative frequencies and the one-way ANOVA test to determine significance of differences of mean egg counts.

\section{Results}

A total of 396 dogs, consisting of 180 (45.5\%) males and 216 (54.5\%) females was examined; 192 (48\%) dogs lived in urban, and 204 (52\%) in rural areas.

All dog owners agreed to participate and completed the questionnaires. Table 1 summarizes the differences in dog regimen and the perception of dog owners to diseases transmissible by their animals, stratified by urban and rural areas. In the rural area, significantly more individuals kept dogs for hunting and observed their dogs catching prey than in the city $(p<0.0001)$, whereas $29.2 \%$ and $18.1 \%$ of dog owners in the urban and rural areas kept dogs as watch dogs, respectively (Table 1 ). Treatment with antiparasitic drugs was a more frequent practice for dogs from urban than rural areas.

Interestingly, more than half of dog owners in the rural communities, and about a third in the urban area did not perceive diseases transmitted by dogs as a health problem $(p<0.0001)$. The bonds of humans with their animals were close, and children played with virtually all dogs included in the study (Table 1). When asked about possible diseases transmitted by their dogs, less than $10 \%$ of owners mentioned helminths ("worms") as a health problem, but about two third were aware of the risk of rabies transmission (Table 1 ).

\section{Ectoparasites}

At least one of nine ectoparasite species identified, belonging to four taxa, was encountered in 239 (60.4\%) of the 396 dogs. Dogs from rural areas $(77.9 \%)$ were more commonly infested than those from urban areas $(41.7 \%$; $p<0.0001)$. Eighty $(20.3 \%)$ dogs harboured two or more species. Dogs from rural areas were more frequently parasitized with two or more ectoparasites than the urban dogs (Table 2).

In total, 155 (39.1\%) were infested with fleas, 94 (23.7\%) with ticks, $51(12.9 \%)$ with mites, and $42(10.6 \%)$ with lice. The prevalence detailed for each ectoparasite species is depicted in Table 2, stratified by urban and rural areas.

The common dog flea, Ctenocephalides canis, was the most prevalent species and present in almost one third of dogs, followed by the brown dog tick Rhipicephalus sanguineus, Trichodectes canis, Otodectes sp., Pulex irritans and Ixodes sp. (Table 2). Infestations due to the sand flea Tunga penetrans, the mange mite Sarcoptes scabiei var. canis and Demodex canis were less common.

The prevalence of C. canis and of Otodectes sp. was significantly higher in rural dogs than in urban dogs. A similar trend was observed for $P$. irritans and $R$. sanguineus (Table 2).

\section{Intestinal helminths}

In total, $271(68.4 \%)$ of the examined dogs were infected with at least one intestinal helminth species. Six species, namely Toxocara canis, Ancylostoma sp.Trichuris vulpis, Dipylidium caninum, Taenidae and Strongyloides sp. were identified in dogs of both urban and rural areas (Table 3 ). 
Table I: Characteristics of dogs and knowledge and attitudes of dog owners regarding potential zoonotic disease in urban and rural communities.

\begin{tabular}{|c|c|c|c|c|c|}
\hline \multirow[t]{2}{*}{ Variables } & \multicolumn{2}{|c|}{ Urban $n=192$} & \multicolumn{2}{|c|}{ Rural $n=204$} & \multirow{2}{*}{$\begin{array}{l}\text { Urban Vs. rural } \\
p \text { value }\end{array}$} \\
\hline & $\mathrm{N}$ & $\%$ & $N$ & $\%$ & \\
\hline \multicolumn{6}{|l|}{ Sex of dogs } \\
\hline Male & 91 & $47.4 \%$ & 89 & $43.6 \%$ & 0.5 \\
\hline Female & 101 & $52.6 \%$ & 115 & $56.4 \%$ & 0.5 \\
\hline \multicolumn{6}{|l|}{ Age of dogs (months) } \\
\hline $0-6$ & 61 & $31.8 \%$ & 73 & $35.8 \%$ & 0.4 \\
\hline $7-11$ & 49 & $25.5 \%$ & 59 & $28.9 \%$ & 0.4 \\
\hline$\geq 12$ & 82 & $42.7 \%$ & 72 & $35.3 \%$ & 0.1 \\
\hline \multicolumn{6}{|l|}{ Reasons for keeping dogs } \\
\hline Hunting & 7I & 37.0 & 115 & 56.4 & $<0.0001$ \\
\hline Watch dog & 56 & 29.2 & 37 & 18.1 & 0.013 \\
\hline Companion & 43 & 22.4 & 32 & 15.7 & 0.1 \\
\hline No specific reason & 22 & 11.5 & 20 & 9.8 & 0.6 \\
\hline \multicolumn{6}{|l|}{ Where do dogs usually roam? } \\
\hline Confined to dog house on compound & 18 & 9.4 & 7 & 3.4 & 0.022 \\
\hline Inside the house & 3 & 1.6 & 11 & 5.4 & 0.055 \\
\hline Within the compound & 57 & 29.7 & 33 & 16.2 & 0.002 \\
\hline Anywhere within and outside the compound & 114 & 59.4 & 153 & 75.0 & 0.001 \\
\hline \multicolumn{6}{|l|}{ How do dogs leave house premises } \\
\hline Always accompanied & 35 & 18.2 & 10 & 4.9 & $<0.0001$ \\
\hline Occasionally accompanied & 67 & 34.9 & 80 & 39.2 & 0.4 \\
\hline Never Accompanied & 90 & 46.9 & 114 & 55.9 & 0.09 \\
\hline \multicolumn{6}{|l|}{ Usual place of defecation } \\
\hline Within the house premises & 66 & 34.4 & 54 & 26.5 & 0.1 \\
\hline Within/out of house premises & 126 & 65.6 & 150 & 73.5 & 0.1 \\
\hline \multicolumn{6}{|l|}{ Preferred type of floor where dogs defecate } \\
\hline Only impervious (cemented/tiles) & 29 & 15.1 & 16 & 7.8 & 0.027 \\
\hline Only pervious (grass, soil, etc) & 56 & 29.2 & 86 & 42.2 & 0.009 \\
\hline Both pervious/impervious & 107 & 55.7 & 102 & 50.0 & 0.3 \\
\hline Observation on dogs catching prey & 118 & 61.5 & 164 & 80.4 & $<0.0001$ \\
\hline \multicolumn{6}{|l|}{ Last anthelminthic treatment of dogs } \\
\hline$<12$ months ago & 42 & 21.9 & 20 & 9.8 & 0.001 \\
\hline$\geq 12$ months ago & 56 & 29.2 & 38 & 18.6 & 0.018 \\
\hline Never & 94 & 49.0 & 146 & 71.6 & $<0.0001$ \\
\hline \multicolumn{6}{|c|}{ Dog owners' knowledge of possible diseases/conditions transmitted or caused by dogs* } \\
\hline Rabies & 124 & 64.6 & 136 & 66.7 & 0.7 \\
\hline Wound from dog bite & 75 & 39.1 & 85 & 41.7 & 0.6 \\
\hline Scabies & 35 & 18.2 & 28 & 13.7 & 0.3 \\
\hline Worms & II & 5.7 & 15 & 7.4 & 0.5 \\
\hline Dysentery & 6 & 3.1 & 10 & 4.9 & 0.4 \\
\hline Other bacterial/viral diseases & 5 & 2.6 & 12 & 5.9 & 0.14 \\
\hline \multicolumn{6}{|l|}{ Do children play with dogs? } \\
\hline Yes & 191 & 99.5 & 204 & 100 & 0.5 \\
\hline No & 1 & 0.5 & 0 & 0 & 0.5 \\
\hline \multicolumn{6}{|c|}{ Dog owners' perception of diseases transmitted by dogs } \\
\hline Serious & 35 & 18.2 & 23 & 11.3 & 0.064 \\
\hline Not serious & 91 & 47.4 & 72 & 35.3 & 0.019 \\
\hline Do not cause any disease & 66 & 34.4 & 109 & 53.4 & $<0.0001$ \\
\hline
\end{tabular}

*more than one option possible 
Table 2: Prevalence of ectoparasites in dogs, stratified by urban or rural communities.

\begin{tabular}{|c|c|c|c|c|c|c|c|}
\hline & \multicolumn{2}{|c|}{ Overall $(n=396)$} & \multicolumn{2}{|c|}{ Urban $(n=192)$} & \multicolumn{2}{|c|}{ Rural $(n=204)$} & \multirow{2}{*}{$\begin{array}{l}\text { Urban vs. Rural } \\
p \text { value }\end{array}$} \\
\hline & $\mathrm{N}$ infected & $\%(95 \% \mathrm{Cl})$ & $\mathrm{N}$ infected & $\%(95 \% \mathrm{Cl})$ & $N$ infected & $\%(95 \% \mathrm{Cl})$ & \\
\hline \multicolumn{8}{|l|}{ Fleas } \\
\hline Ctenocephalides canis & 127 & $32.1(27.5-6.9)$ & 40 & $20.8(14.9-26.7)$ & 87 & $42.6(35.8-49.7)$ & $<0.0001$ \\
\hline Pulex irritans & 26 & $6.6(4.3-9.5)$ & 7 & $3.6(1.5-7.4)$ & 19 & $9.3(5.7-14.2)$ & 0.026 \\
\hline Tunga penetrans & 2 & $0.5(0.0-1.8)$ & 0 & 0.0 & 2 & $1.0(0.0-3.5)$ & 0.5 \\
\hline \multicolumn{8}{|l|}{ Mites } \\
\hline Demodex canis & 4 & $1.0(0.0-2.6)$ & 0 & 0.0 & 4 & $2.0(0.0-4.9)$ & 0.12 \\
\hline Otodectes sp. & 39 & $9.8(7.1-13.2)$ & 6 & $3.1(1.2-6.7)$ & 33 & $16.2(11.4-22.0)$ & $<0.0001$ \\
\hline Sarcoptes scabiei var. canis & 8 & $2.0(0.1-3.4)$ & I & $0.5(0.0-2.9)$ & 7 & $3.4(1.3-6.9)$ & 0.069 \\
\hline \multicolumn{8}{|l|}{ Ticks } \\
\hline Rhipicephalus sanguineus & 76 & $19.2(15.4-23.4)$ & 25 & $13.0(8.6-18.6)$ & 51 & $25.0(19.2-31.5)$ & 0.003 \\
\hline Ixodes sp. & 18 & $4.5(2.7-7.1)$ & 7 & $3.6(1.5-7.4)$ & 11 & $5.4(2.7-9.4)$ & 0.5 \\
\hline \multicolumn{8}{|l|}{ Lice } \\
\hline Trichodectes canis & 42 & $10.6(7.8-14.1)$ & 15 & $7.8(4.4-12.6)$ & 27 & $13.2(8.9-18.7)$ & 0.1 \\
\hline \multicolumn{8}{|c|}{ Number of ectoparasite species per host } \\
\hline One ectoparasite species & 159 & $40.2(35.3-45.2)$ & 60 & $31.3(24.8-38.3)$ & 99 & $48.5(41.5-55.6)$ & $<0.0001$ \\
\hline Two ectoparasite species & 72 & $18.2(14.5-22.3)$ & 19 & $9.9(6.1-15.0)$ & 53 & $26.0(20.1-32.6)$ & $<0.0001$ \\
\hline Three ectoparasite species & 7 & $1.8(0.7-3.6)$ & I & $0.5(0.0-2.9)$ & 6 & $2.9(1.1-6.3)$ & 0.12 \\
\hline $\begin{array}{l}\text { Four or more ectoparasite } \\
\text { species }\end{array}$ & 1 & $0.3(0.0-1.4)$ & 0 & 0.0 & I & $0.5(0.0-2.7)$ & 1.0 \\
\hline
\end{tabular}

The most common parasites were T. canis, followed by Ancylostoma sp. and T. vulpis (Table 3). Prevalence of the dog tapeworm, D. caninum, Taenidae and Strongyloides sp. were $<10 \%$.

Except for D. caninum, Taenidae and Strongyloides sp., the prevalence of intestinal helminths was not statistically different in urban or rural areas. However, multiple infections with 2 and 3 parasites species per host were significantly higher in rural than in urban areas (Table 3 ).

The pattern of prevalence and distribution of helminth parasites, stratified by age of dogs, is depicted in Figure 2 . In general, prevalence of parasite infection increased with age of the dog. An exception was observed in T. canis infection, which was by far the most common infection in puppies, and showed decreasing prevalence with age. The density of infection, expressed by mean egg counts per gramme (epg) paralleled the prevalence data (Table 4).

\section{Discussion}

The present study provides the first systematic assessment on quantitative estimates of parasites in dogs in Nigeria's Kwara State. The results show that ectoparasitic and intestinal helminth species were abundant, and that prevalence and density of infection was very high. The knowledge and perception of dog owners regarding zoonotic diseases transmitted by pets was insufficient.

Table 3: Prevalence of intestinal helminths parasite in dogs, stratified by communities.

\begin{tabular}{|c|c|c|c|c|c|c|c|}
\hline & \multicolumn{2}{|c|}{$\begin{array}{l}\text { Overall } \\
(n=396)\end{array}$} & \multicolumn{2}{|c|}{$\begin{array}{l}\text { Urban } \\
(n=192)\end{array}$} & \multicolumn{2}{|c|}{$\begin{array}{c}\text { Rural } \\
(n=204)\end{array}$} & \multirow{2}{*}{$\begin{array}{l}\text { Urban vs. Rural } \\
p \text { value }\end{array}$} \\
\hline & $\mathrm{N}$ infected & $\%(95 \% \mathrm{Cl})$ & $\mathrm{N}$ infected & $\%(95 \% \mathrm{Cl})$ & $\mathrm{N}$ infected & $\%(95 \% \mathrm{Cl})$ & \\
\hline \multicolumn{8}{|l|}{ Parasite species } \\
\hline Toxocara canis & 165 & $41.7(36.8-46.7)$ & 72 & $37.5(30.6-44.8)$ & 93 & $45.6(39.6-53.7)$ & 0.13 \\
\hline Ancylostoma sp. & 67 & $16.9(13.4-21.0)$ & 27 & I4.I (9.5 - 19.8) & 40 & $19.6(14.4-25.7)$ & 0.18 \\
\hline Trichuris vulpis & 57 & $14.4(9.7-16.6)$ & 28 & $14.6(9.9-20.4)$ & 29 & $14.2(9.7-19.8)$ & 1.0 \\
\hline Dipylidium caninum & 36 & $9.1(6.5-12.4)$ & 11 & $5.7(2.9-10.0)$ & 25 & $12.3(8.1-17.6)$ & 0.035 \\
\hline Taenidae & 33 & $8.3(5.8-11.5)$ & 3 & $1.6(0.3-4.5)$ & 30 & $14.7(10.2-20.3)$ & $<0.0001$ \\
\hline Strongyloides sp. & 15 & $3.8(2.1-6.2)$ & 3 & $1.6(0.3-4.5)$ & 12 & $5.8(3.1-10.1)$ & 0.033 \\
\hline \multicolumn{8}{|c|}{ Number of intestinal helminth species per host } \\
\hline One helminth species & 196 & $49.4(44.2-54.3)$ & 92 & $47.9(40.7-55.2)$ & 104 & $51.0(43.9-58.3)$ & 0.6 \\
\hline Two helminth species & 52 & $13.1(10.0-16.9)$ & 17 & $8.9(5.2-13.8)$ & 35 & $17.5(12.3-23.0)$ & 0.017 \\
\hline Three helminth species & 18 & $4.6(2.7-7.1)$ & 4 & $2.1(0.6-5.2)$ & 14 & $6.9(3.8-11.2)$ & 0.029 \\
\hline $\begin{array}{l}\text { Four or more helminth } \\
\text { species }\end{array}$ & 5 & $1.3(0.0-2.9)$ & 0 & - & 5 & $2.5(0.1-5.6)$ & 0.062 \\
\hline
\end{tabular}




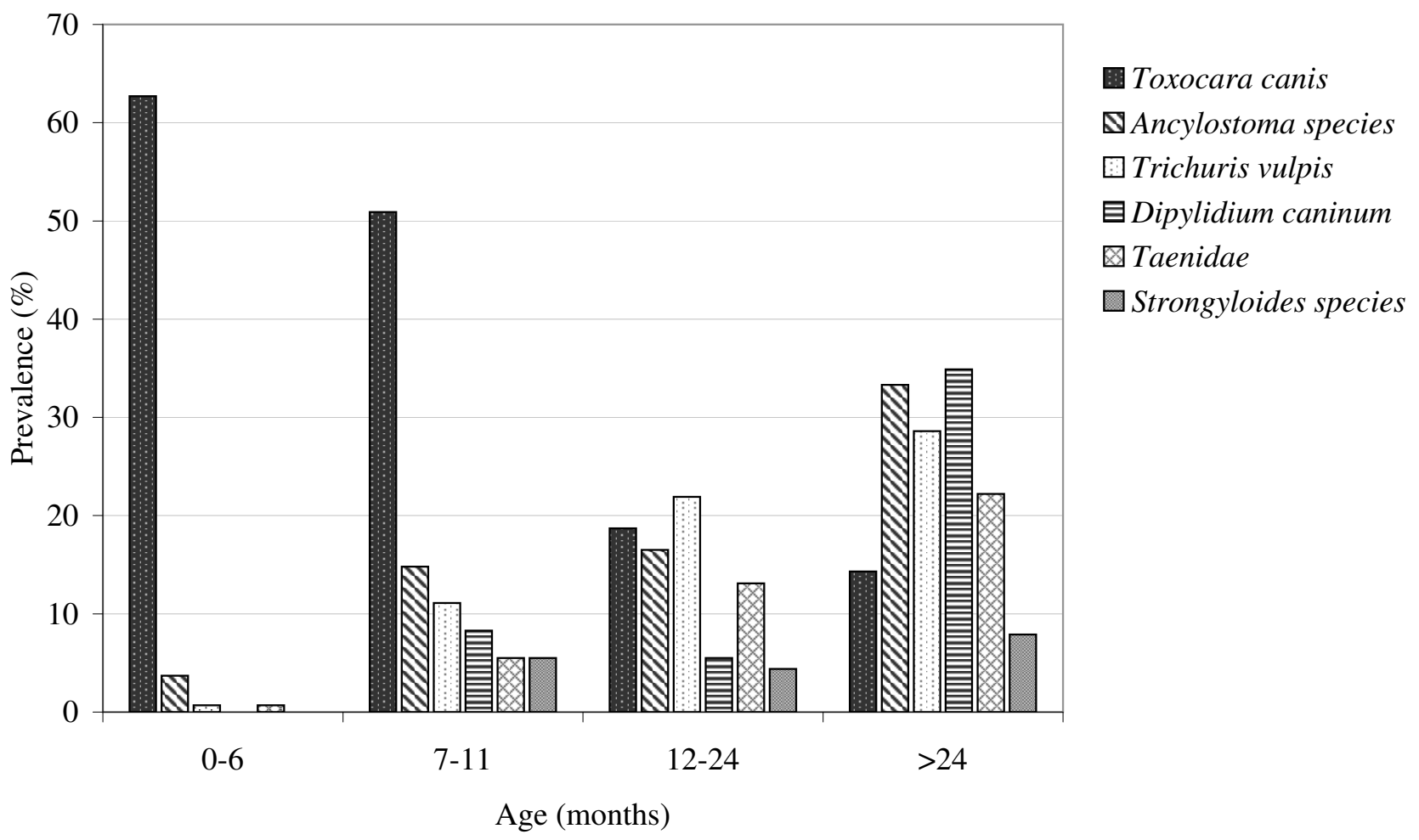

Figure 2

Prevalence of intestinal helminths species diagnosed in dogs, stratified by age of dogs.

The parasites reported in this study have been previously documented in dogs throughout the world, with a pronounced difference in prevalence and density between regions $[16,17,20-27]$. In our study, the overall prevalence of intestinal helminths $(68 \%)$ was similar to that reported from different ecological and epidemiological settings in Nigeria $[17,26]$ and to the prevalence of $71 \%$ reported from Spain [28]. In South Africa (76\%), Mexico (85\%) and Morocco $(100 \%)$, prevalences were even higher $[22,23,29]$.
This potential for human zoonotic disease has rarely been addressed in control programs in Nigeria and other low income countries. Considering the high prevalence of ectoparasites and intestinal helminth infections found in dogs, and the close bonds in which dogs live together with people, the risk of transmission of these parasites to humans seems to be obvious. For example, Toxocara infection in humans may cause visceral larva migrans, in severe cases leading to blindness [30], and dog hookworm infections put humans at risk for cutaneous larva migrans

Table 4: Density of intestinal parasites infection in dogs, stratified by rural and urban communities.

\begin{tabular}{|c|c|c|c|c|}
\hline Parasite & $\begin{array}{l}\text { Overall } \\
n=396\end{array}$ & $\begin{array}{c}\text { Urban } \\
n=192\end{array}$ & $\begin{array}{c}\text { Rural } \\
n=204\end{array}$ & Urban vs. Rural \\
\hline & Mean (SD) & Mean (SD) & Mean (SD) & $p$ value \\
\hline Toxocara canis & $375.6(569.5)$ & 264.I (44I.3) & 480.47 (651.9) & 0.001 \\
\hline Ancylostoma sp. & $84.2(221.5)$ & $70.4(207.6)$ & $97.29(233.5)$ & 0.54 \\
\hline Trichuris vulpis & | 47.8 (440.6) & $126.23(404.2)$ & $168.12(477.4)$ & 0.79 \\
\hline Dipylidium caninum & 46.8 (189.7) & $10.12(85.9)$ & $81.29(246.2)$ & 0.028 \\
\hline Taenidae & $126.8(435.0)$ & $77.38(336.6)$ & $173.29(507.1)$ & 0.001 \\
\hline Strongyloides sp. & I I.3 (68.1) & $7.25(57.8)$ & $15.18(76.5)$ & 0.92 \\
\hline
\end{tabular}


which is endemic in many resource-poor communities [31]. Rhipicephalus ticks have been described to parasitize humans [32], and may transmit rickettsial disease and visceral leishmaniasis [33]. Fleas may transmit human plague, rickettsioses and trypanosomes [34], and serve as intermediate hosts for the dog tapeworm, D. caninum.

Our data show that the prevalence pattern was agedependent; $T$. canis decreased with age of dog, whereas $A$. caninum, T. vulpis, Taenidae, D. caninum and Strongyloides sp. increased with age, even though to a less extent. These patterns have been observed previously $[16,17,20,23,27]$. In Nigeria, Sowemimo and Asaolu [27] found by far the highest prevalence of toxocariasis in puppies, whereas the age dependency of hookworm infection was less pronounced. The high prevalence of ascarid infections in puppies is in accordance with the transmission pattern of the parasite, which is mainly by transplancental and transmammary routes; acquired age-dependent immunity may be caused by repeated exposure $[35,36]$. Increased infection rates in older dogs are caused by parasite species which are not transmitted to dogs at early age, and thus do not elicit a specific immune response.

The prevalence detected in our study differs from those of Sowemimo and Asaolu [27] who recorded 24\% in a Nigerian city in a neighbouring state with similar characteristics as Ilorin. However, these data were not populationbased, but included dogs presented to veterinary clinics. These authors also argued that the reduction of prevalence as compared to a study done in the 1970s [31] may be caused by increased awareness of pet holders regarding deworming practices. In contrast, our data can be regarded as representative for the dog population, as pet owners who bring their animals to veterinary clinics may deworm their animals more regularly. As a consequence, studies based on veterinary clinics underestimate prevalence of parasitic infections and infestations. Our data, though, show that the majority of dogs received antiparasitic treatment never or more than a year ago, and only few people were aware of the zoonotic potential of dog parasites; $60 \%$ of dogs examined had never visited a clinic for any form of treatment.

The reduced prevalence of $D$. caninum over time was claimed to be caused by the reduced prevalence of the intermediate host $C$. canis. This may hold true for pets brought to veterinary clinics, but our study shows that $C$. canis is very common in dogs in the community and thus probably continue being important for the transmission of D. caninum.

The intensities of T. canis, Taenidae and D. caninum were statistically higher in rural dogs than those in the urban area. Similarly, Habluetzel et al. [38] observed that twice as many dogs from rural areas had nematodes infections, as compared to urban dogs. These differences in the level of infection from different locations have been described also in other studies $[39,40]$ and may be partly due to variation in local environmental conditions affecting spatial aggregation and infective stages of parasites. Besides, differences in health care and animal management practices may account for these differing characteristics. Urban dog owners may feel encouraged by their proximity to veterinary clinics, which are nonexistent in rural areas.

The number of intestinal parasite species per host revealed that single infection was more common; polyparasitism with more than two parasites species was less frequently observed. A similar pattern was observed in ectoparasite infestation. These results are in agreement with Fontanarrosa et al. [24] who explained that interactions among parasite species depend on parasite burden rather than the mere presence of other species.

The high prevalence of ectoparasites (60\%) was consistent with another study, where fleas and ticks were the most commonly found taxa [41]. Ugochukwu and Nnadozie [42] recorded in Bendel State (Nigeria) a low prevalence of ectoparasites in dogs, including Demodex canis, R. sanguineus and C. canis. Bryson et al. [43] identified several species of ixodid ticks, fleas and lice from dogs in South Africa. However, C. felis and Echidnophaga gallinacea which were frequently reported in dogs in other study areas $[39,42-44]$ were not encountered in our study.

The variation in distribution and prevalence of ectoparasites can be ascribed to differences in the availability of infective stages, host habitat/climatic factors and the sampling period. Peak prevalences of ectoparasites usually occur during the warm dry months $[40,45,46]$. Gracia et al. [40] revealed that accumulation of organic wastes and the presence of other pet animals influence the survival and abundance of ectoparasites, especially fleas. This also explains why $P$. irritans and $T$. penetrans, relatively low host-specific ectoparasites, occurred only in rural areas, where dogs were frequently in contact with other natural host animals, such as pigs, rats and small ruminants [4749].

Unfortunately, due to the absence of funding, we were unable to identify the prevalence of other zoonotic diseases and to specify the species in Taenidae encountered, such as Echinococcous granulosus causing hydatid disease. The diagnostic technique of parasites done in this study, based on the morphological characteristics of ova under light microscope, has the disadvantage that it fails to distinguish E. granulosus from other Taenidae. Thus, E. granulosus, a major zoonotic parasite of livestock and dogs in Nigeria $[11,14,15]$, has possibly been present but not 
reported in our survey. The fact that dogs enjoy unrestrained association with humans, scavenge for food in an environment contaminated with faecal material of potential intermediate hosts and feed on offal of slaughtered livestock in abattoirs (Ugbomoiko, personal communication) makes transmission of hydatid disease predictable in the setting studied.

In general, the trend in prevalence, density and species composition of parasites observed in this study may reflect the degree of environmental contamination and inequalities in the health care service between urban and rural areas. In particular, T. canis, A. caninum and D. caninum are zoonotic parasites constituting public health problems in the study areas.

\section{Conclusion}

Our study shows that parasites of importance for human health were highly prevalent in Nigerian dogs and that intervention measures are necessary to reduce the risk of transmission of parasites from dogs to humans. Interventions should focus on health education provided to dog owners and the establishment of a program based on zoonotic diseases.

\section{Authors' contributions}

USU: study design, conducted the study, statistical analysis, contributed to the manuscript; LA: statistical analysis, contributed to the manuscript; JH: study design, statistical analysis, contributed to the manuscript. All authors read and approved the final manuscript.

\section{Acknowledgements}

LA received a PhD scholarship from Coordenação de Aperfeiçoamento de Pessoal de Nivel Superior (CAPES/Brazil). The study was supported in part by a PROÁFRICA grant from the Conselho Nacional de Desenvolvimento Científico e Tecnológico ( $\mathrm{CNPq} / \mathrm{Brazil})$. JH is research fellow from CNPq.

\section{References}

I. Dohoo IR, McDonell WN, Rhodes CS, Elazhary YL: Veterinary research and human health. Can Vet J 1998, 39:549-556.

2. Robertson ID, Irwin PJ, Lymbery AJ, Thompson RCA: The role of companion animals in the emergence of parasitic disease. Int J Parasitol 2000, 30:1369-1377.

3. McCarthy J, Moore T: Emerging helminth zoonoses. Int J Parasitol 2000, 30:135I-1360.

4. Molyneux DH: 'Neglected' Diseases but unrecognized successes-challenges and opportunities for infectious disease control. Lancet 2004, 364:380-383.

5. Dakkak A: Echinococcus-hydatidiosis in North Africa: geographical distribution of species and strains and prevalence in man and animals. In Guidelines for diagnosis, surveillance and control of echinococcosis Veterinary Public Health, World Health Organization, Geneva Switzerland; 1992.

6. Heukelbach J, Mencke N, Feldmeier H: Cutaneous larva migrans and tungiasis: the challenge to control zoonotic ectoparasitoses associated with poverty. Trop Med Int Health 2002, 7:907-910.

7. Heukelbach J, Wilcke T, Meier A, Moura RCS, Feldmeier H: A longitudinal study of cutaneous larva migrans in an impoverished Brazilian township. Travel Med Infect Dis 2003, I:213-218.
8. Akao N, Ohta N: Toxocariasis in Japan. Parasitol Int 2007, 56:87-93.

9. Morrison G: Zoonotic infection from pets. Understanding the risk and treatment. Postgrad Med 200I, I I 0:24-26.

10. Irwin PJ: Companion animal parasitology: clinical perspective. Int J Parasitol 2002, 32:59|-593.

II. Dada BJO, Adeboye DS, Mohammed AN: The epidemiology of Echinococcus infection in Kaduna State, Nigeria. Vet Rec I979, 104:3|2-313.

12. Malgor R, Oku Y, Gallardo R, Yarzabal I: High prevalence of Ancylostoma species infection in dogs associated with endemic focus of human cutaneous larva migrans in Tacuaremba Uruguay. Parasite 1996, 3:131-134.

13. Patz JA, Gractzyk TK, Gella N, Vittor AY: Effects of environmental changes on emerging parasitic diseases. Int J Parasitol 2002, 30: I395-1405.

14. Dada BJO: Taeniasis, cysticercosis and echinococcosis/hydatidiosis in Nigeria: iv. Prevalence of Echinococcus granulosus infection in stray dogs. J Helminthol 1980, 54:299-301.

15. Ayanwale FO, Dipeolu OO, Esuruoso GO: The incidence of Echinococcus infection in dogs, sheep and goats slaughtered in Ibadan, Nigeria. Int J Zoonoses 1982, 9:65-68.

16. Chiejina SN, Ekwe TO: Canine toxocariasis and the associated environmental contamination of urban areas in Eastern Nigeria. Vet Parasitol 1986, 22:157-161.

17. Anene BM, Nnaji TO, Chime AB: Intestinal Parasitic infections of dogs in the Nsukka area of Enugu, Nigeria. Prev Vet Med 1996, 27:89-94.

18. Forrester JE, Scott ME: Measurement of Ascaris infection intensity and dynamic of expulsion following treatment with Mebendazole. Parasitology 1990, 100:303-308.

19. Pitchford RJ, Visser PS: A simple rapid technique for quantitative estimation of helminthes eggs in human and animals excreta with special reference to Schistosoma species. Trans $R$ Soc Trop Med Hyg 1975, 69:318-322.

20. Ugochukwu El, Ejimadu KN: Studies on the prevalence of gastrointestinal helminths of dogs in Calabar Nigeria. Int J Zoonoses 1985, 12:214-218.

21. Oliveira-Sequeira TCG, Amarante AFT, Ferrari TB, Nunes LC: Prevalence of intestinal parasites in dogs from São Paulo State, Brazil. Vet Parasitol 2002, 103:19-27.

22. Minnaar WN, Krecek RC, Fourie LJ: Helminths in dogs from a peri-urban resource-limited community in Free State Province, South Africa. Vet Parasitol 2002, 107:343-349.

23. Eguia-Aguilar P, Cruz-Reyes A, Martinez-Maya J]: Ecological analysis and description of the intestinal helminthes present in dogs in Mexico City. Vet Parasitol 2005, I 27: I 39-I46.

24. Fontanarrosa MF, Vezzani D, Basabe J, Eiras D: An epidemiological study of gastrointestinal parasites of dogs from Southern Greater Buenos Aires (Argentina): Age, gender, breed, mixed infections, and seasonal and spatial patterns. Vet Parasitol 2006, I 36:283-295.

25. Yacob HT, Ayele T, Fikru R, Basu AK: Gastrointestinal nematodes in dogs from Debre Zeit, Ethiopia. Vet Parasitol 2007, I 48: | $44-$ | 48 .

26. Omudu EA, Amutu EU: Parasitology and urban livestock farming in Nigeria: Prevalence of ova in faecal and soil samples and animals ectoparasites in Makurdi. J S Afr Vet Assoc 2007, 78:40-45.

27. Sowemimo OA, Asaolu SO: Epidemiology of intestinal helminth parasites of dogs in Ibadan, Nigeria. J Helminthol 2008, 82:89-93.

28. Martinez-Moreno FJ, Hernandez S, Lopez-Cobos E, Becerra C Acosta I, Martinez-Moreno A: Estimation of canine intestinal parasites in Cordoba (Spain) and their risk to public health. Vet Parasitol 2007, 143:7-13.

29. Pandey VS, Dakkak A, Elmamoune M: Parasites of stray dogs in Rabat region, Morocco. Ann Trop Med Parasitol 1987, 81:53-55.

30. Taylor MR: The epidemiology of ocular toxocariasis. Helminthol 2001, 75:109-118.

31. Heukelbach J, Walton SF, Feldmeier H: Ectoparasitic infestations. Curr Infect Dis Rep 2005, 7:373-380.

32. Dantas-Torres F, Figueredo LA, Brandao-Filho SP: Rhipicephalus sanguineus (Acari: ixodidae), the brown dog tick, parasitizing humans in Brazil. Rev Soc Bras Med Trop 2006, 39:64-67.

33. Coutinho MT, Bueno LL, Sterzik A, Fujiwara RT, Botelho JR, De Maria M, Genaro O, Linardi PM: Participation of Rhipicephalus san- 
guineus (Acari: Ixodidae) in the epidemiology of canine visceral leishmaniasis. Vet Parasitol 2005, I 28( I-2): | 49 - I55.

34. Zanatta-Coutinho MT, Linardi PM: Can fleas from dogs infected with canine visceral leishmaniasis transfer the infection to other mammals? Vet Parasitol 2007, 147:320-325.

35. Sprent JFA: Post-parturient infection of the bitches with Toxocara canis. J Parasitol 196I, 47:284.

36. Sprent JFA: Observation on the development of Toxocara canis (Werner, 1782) in the dogs. Parasitology 1957, 48: I 84-193.

37. Olufemi BE, Bobade PA: Prevalence of gastrointestinal helminth parasites of dogs in Ibadan, Nigeria. Nig Vet J 1979, 23:2I-25.

38. Habluetzel A, Traldi G, Ruggieri S, Attili AR, Scuppa P, Marchetti R, Menghini G, Esposito F: An estimation of Toxocara canis prevalence in dogs, environmental egg contamination and risk of human infection in the Marche region of Italy. Vet Parasitol 2003, I 13:243-252.

39. Durden LA, Judy TN, Martin JE, Spedding LS: Fleas parasitizing domestic dogs in Georgia, USA: Species composition and seasonal abundance. Vet Parasitol 2005, I30:157-162.

40. Gracia MJ, Calvete C, Estrada R, Castillo JA, Peribañez MA, Lucientes $\mathrm{J}$ : Fleas parasitizing domestic dogs in Spain. Vet Parasitol 2008 | 5 |:301-309.

41. Estares L, Chavez A, Casas E: Prevalencia de ectoparasitos de Canis familiaris en los dos distritos de San Juan de Lurigancho, San Martin de Porres Comas e Independencia de Lima Metropolitana. Revista de Investigaciones Veterinarias del Perú 1999, 10:1-9.

42. Ugochukwu El, Nnadozie CC: Ectoparasitic infestation in dogs in Bendel State, Nigeria. Int J Zoonoses 1985, I 2:308-3 I2.

43. Bryson NR, Horak IG, Hohn EW, Louw JP: Ectoparasites of dogs belonging to people in resource poor communities in North West Province, South Africa. J S Afr Vet Assoc 2000, 7 1: I75- 179.

44. Gonzalez A, Castro DC, Gonzalez S: Ectoparasitic species of Canis familiaris (Linne) in Buenos Aires Province, Argentina. Vet Parasitol 2004, I 20: I 23-129.

45. Dipeolu OO: A survey of the ectoparasitic infestations of dogs in Nigeria. J Small Anim Pract 1975, 16:123-I29.

46. Heukelbach J, Wilcke T, Harm G, Feldmeier H: Seasonal variation of tungiasis in an endemic community. Am J Trop Med Hyg 2005, 72:145-149.

47. Obasaju MF, Otesile EB: Ctenocephalides canis infestation of sheep and goats. Trop Anim Health Prod 1980, I2:1 16-118.

48. Heukelbach J, Costal AM, Wilcke T, Mencke N, Feldmeier H: The animal reservoir of Tunga penetrans in severely affected community of North east Brazil. Med Vet Entomol 2004, 1 8:329-335.

49. Ugbomoiko US, Ariza L, Heukelbach J: Pigs are the most important animal reservoir for Tunga Penetrans (Jigger flea) in rural Nigeria. Trop Doct 2008, 30:226-227.
Publish with Bio Med Central and every scientist can read your work free of charge

"BioMed Central will be the most significant development for disseminating the results of biomedical research in our lifetime. "

Sir Paul Nurse, Cancer Research UK

Your research papers will be:

- available free of charge to the entire biomedical community

- peer reviewed and published immediately upon acceptance

- cited in PubMed and archived on PubMed Central

- yours - you keep the copyright
BioMedcentral 